\title{
GOODS ROBOTS BASED ON COLOR USING MICROCONTROLLER ATMEGA 328
}

\author{
Ade Titin Sumarni ${ }^{1}$, Novi Rahayu ${ }^{2}$ \\ Universitas Prof. Dr. Hazairin, $\mathrm{SH}^{1}$, Sekolah Tinggi Ilmu Administrasi Bengkulu ${ }^{2}$ \\ adetitin@unihaz.ac.id ${ }^{1}$, novierahayu1980@gmail.com²
}

Received : 25 August 2020, Revised: 18 October 2020 , Accepted : 19 October 2020

\begin{abstract}
Robot is an electrical or electronic mechanical device that works automatically that can work alone without outside control. By using robots in production activities, the process will be more efficient and effective. In this study, robots are made using a microcontroller as a robot controller and color detector to separate goods based on color. Color sensor is useful for getting color data. The detected color consists of Red, Green, Blue, all colors are processed in a microcontroller that functions as the brain in the robot that is made.
\end{abstract}

Keywords : Robot, Color Detection, Microcontroller.

\section{Introduction}

Technological developments have experienced many innovations, one of which is robotics technology. This can be seen from the resulting innovations and the occurrence of social interactions between technology and human life, which causes technology to be a part of human life. The emergence of technology is one of the demands and needs to facilitate human work(Boyd \& Holton, 2018).

Basically, a robot is an electrical or electronic mechanical device that works automatically that can work alone without outside control. Meanwhile, in a broad sense the robot means a system consisting of mechanical mechanisms that have an electrical control to carry out certain tasks. In its development, robots began to be used in all fields including industry in the implementation of its production(Keisner, et. al. 2016).

Color selection is sometimes a problem in determining the color value if seen directly by the human eye, this happens if the human eye is exposed to color blindness but can still see certain colors. The basic principle of color is grouped into 3 basic colors namely R-G-B (RED, GREEN, BLUE) This is the original color space used on computer graphics systems(Sihombing, et. al., 2019).

\section{Literature Review}

The robot is a mechanical device that can do the task of replacing humans, either using human supervision and control, or using a program that has been defined (artificial intelligence). Robots are usually used to replace humans doing heavy, dangerous, repetitive, and dirty work. industry is used in the production line (repetitive work). Another use is to assist humans in moving an object without having to lift the object. These robots are also often applied to industrial plants and can help humans and save time in work(Duan, et. al. 2019).

Microcontroller is a chip or IC (Integrated Circuit) that can be programmed using a computer. The recorded program aims to enable the electronic circuit to read the input, process, and then produce the desired output. The output can be a signal, the amount of voltage, lights, sound, vibration, motion, and so on. Microcontroller is a semiconductor technology consisting of a series of transistors with a small size. Microcontrollers can be used flexibly and effectively in controlling various electronic equipment. Microcontroller can also be called a small-sized computer that is low-power so that a battery can provide power. A standard microcontroller has the following components(Sanchez \& Canton, 2018):

a. Central Processing Unit (CPU) is the main part of a microcontroller. CPUs on microcontrollers are 8 bits or 16 bits. This CPU will read programs stored in ROM and 
implement them. Read Only Memory (ROM) is a memory (a tool to remember) that is only readable. Thus ROM cannot be written. In the world of ROM microcontrollers are used to store programs for the microcontroller. The program is saved in binary format (' 0 ' or ' 1 '). The arrangement of these binary numbers when read by a microcontroller will have its own meaning.

b. Random Access Memory (RAM) is different from ROM, RAM is a type of memory in addition to being readable and can also be written repeatedly. Of course, in the use of microcontrollers there is a kind of data that can change when the microcontroller is working. Changes to the data will of course also be stored in memory. The contents of RAM will be lost if the power supply is lost.

c. Input / Output (I / O) to communicate with the outside world, the microcontroller uses the I / O terminal (I / O port) that is used for input or output.

d. Other components are how many microcontrollers have a timer or counter, ADC (Analog to Digital Converter) and other components. Selection of additional components in accordance with the task of the microcontroller will greatly help the design so that it can maintain its small size. If these components do not yet exist on a microcontroller, generally these components can still be added to the microcontroller system through its ports.

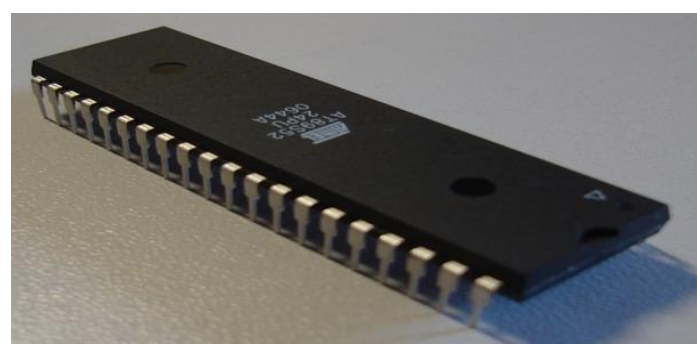

Fig. 1. Microcontroller

\section{Arduino}

Arduino is an open-source single-board micro controller, derived from the Wiring platform, designed to facilitate the use of electronics in various fields. The hardware has the Atmel AVR processor and the software has its own programming language. Arduino UNO is a microcontroller board based on ATmega328 (datasheet)(Rajan, et. al., 2015).

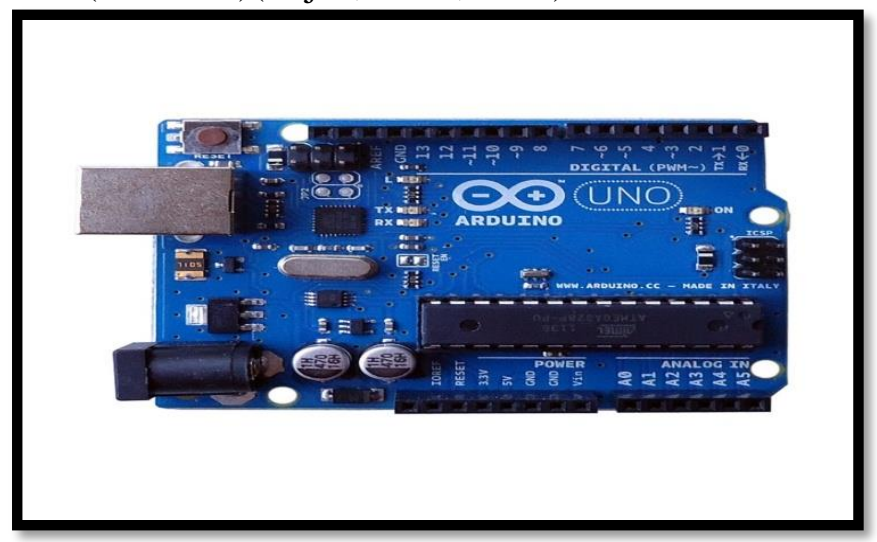

Arduino board parts

Fig. 2. Arduino UNO

1. 14 digital input / output pins (0-13). Functioning as input or output, can be set by the program. Especially for 6 pins 3, 5, 6, 9, 10 and 11, it can also function as an analog output pin where the output voltage can be adjusted. The value of an analog output pin can be programmed between $0-255$, where it represents a voltage value of $0-5 \mathrm{~V}$.

2. USB, functions to:

a) Make a program from the computer into the board

b) Serial communication between the board and the computer 
c) Give electricity to the board

d) SV1 connection

Connection or jumper for selecting board resources, whether from an external source or using USB. Q1-Crystal (quartz crystal oscillator)

3. Reset button S1, To reset the board so that the program will start again from the beginning. Note that this reset button is not for removing programs or emptying the microcontroller.

4. In-Circuit Serial Programming (ICSP). The ICSP port allows users to program the microcontroller directly, without going through the bootloader. Generally Arduino users do not do this so ICSP is not used even though it is provided.

5. 3. IC 1 - Atmega Microcontroller. The main components of the Arduino board, there are CPU, ROM and RAM.

6. 4. X1 - external power source. If you want to be supplied with an external power source, Arduino boards can be given a DC voltage between $9-12 \mathrm{~V}$.

7. 6 analog input pins (0-5). This pin is very useful for reading the voltage generated by analog sensors, such as temperature sensors. The program can read the value of a pin between $0-1023$, where it represents a voltage value of $0-5 \mathrm{~V}$.

\section{Sensor}

A sensor is a device that receives a stimulus or stimulus as a quantity of certain properties or conditions that can be converted into electrical signals. The output of the sensor can be in the form of a current and is often used for detection when measuring and controlling. Sensor characteristics function to determine the performance of the sensor designed. The static characteristics of a sensor are(Meijer, 2008):

a. Accuracy, to determine the inaccuracy of a sensor, as a difference in the value of the calculation with the experimental value.

b. Non Linearity, used for sensors that have the transfer function of a linear approach. Nonlinearity is also a maximum approach and can be done for sensors with non-linear transfer functions that can be used with terminal point and transfer methods.

c. Saturation of each sensor has a limitation of operation although it has a linear transfer function, but at certain inputs it has non-linear transfer.

d. Resolution is the sensor's ability to detect the minimum input signal. When the sensor is input continuously, the output signal on the sensor will not give perfect results. Under these conditions the output changes usually occur, so the sensor is said to have a small resolution.

e. Repeatability occurs because sensors are unable to produce the same values under the same conditions, usually due to temperature disturbances and other environmental conditions.

\section{TCS3200 Color Sensor}

The TCS3200 Color Sensor Module uses the TCS3200 RGB TAOS chip. This module has been integrated with 4 LEDs. The TCS3200 Color Sensor can detect and measure the intensity of visible colors. Some applications that use this sensor include the reading of color groups according to color, ambient light sensing and calibration, color matching, and many other applications. TCS3200 chip has several photodetectors, with each color filter, namely, red, green, blue, and clear. The filters are distributed in each array. This module has an oscillator that produces square pulses with the same frequency as the color detected(Choudhary, et. al., 2018).

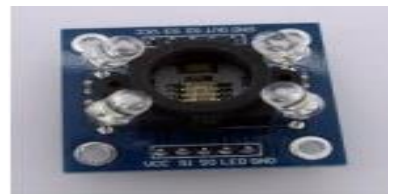

Fig. 3. TCS3200 Color Sensors 


\section{Ultrasonic Sensors}

Ultrasonic is sound or vibration with a frequency that is too high for the human ear to hear. Ultrasonic vibrates in a range greater than 20 Kilo Hertz. Ultrasonic can also be described simply as waves above the frequency of sound waves. Ultrasonic sensors are the main sensor for navigation and obstacle avoidance(Latha, et. al., 2016).

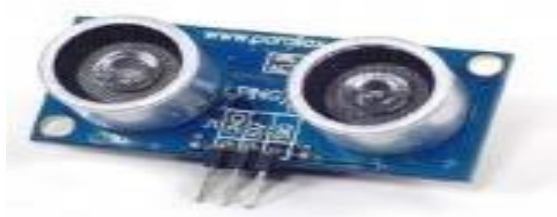

Fig. 4. Ultrasonic

The ultrasonic ping sensor is mounted on the front of the robot, so it is seen as the eye of the robot. This sensor will measure the distance from the objects around it. If the distance detected is very close, it can be concluded that there is an object very close to the sensor. So the robot must avoid by turning or maneuvering in the other direction.

\section{LCD (Liquid Crystal Display)}

LCD (Liquid Crystal Display) is a type of display media that uses liquid crystal as the main viewer. LCDs can display images or writing because there are so many points of light (pixels) that consist of a single liquid crystal as a point of light. Although called a point of light, this liquid crystal does not emit light itself. The light source in an LCD device is a white neon lamp on the back of the liquid crystal array. These points of light, which number in the tens of thousands or even millions, form the appearance of images. The liquid crystal poles that are passed by an electric current will change due to the effect of the polarization of the magnetic field that arises and will therefore only allow some colors to continue while the other colors are filtered out(Rahman, et. al., 2015).

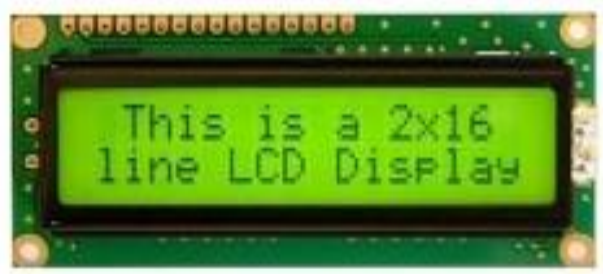

\section{DC motor}

Fig. 5. LCD

DC motor is a motor that uses a DC voltage source and is used to convert electric power into mechanical power. This component works with the electromagnet principle. When a voltage source is applied, a magnetic field in a stationary part called a stator will form. This magnetic field will make the rotor or moving parts rotate and of course can be used to rotate other objects such as wheels. The rotation speed of a DC motor is determined by the voltage. The higher the voltage, the faster the rotation. Too high a voltage, which exceeds the maximum limit, can make the motor burn(Petru \& Mazen, 2015).

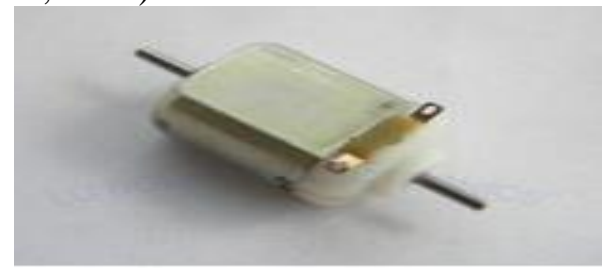

Fig. 6. DC motor

When the DC motor voltage supply is stopped, the magnetic field gradually disappears, while producing a reverse voltage. This back voltage is handled so as not to damage the Arduino 
Uno. The method is to install a diode. It is based on the nature of the diode which can flow electric current only in one direction. have adjusted and the activated segment looks dark and shapes the character of the data you want to display.

\section{Servo Motors}

Servo motors are basically made using DC motors which are equipped with a controller and position sensor so that they can have movements of $0 \mathrm{o}, 90 \mathrm{o}, 180 \mathrm{o}$ or $360 \mathrm{o}$. Here are the internal components of a $180 \mathrm{o}$ servo

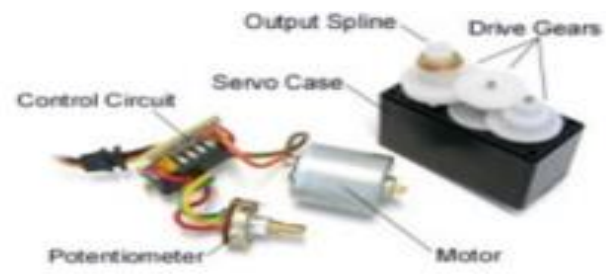

Fig. 7. Servo Motor

Each component on the servo motor above each has a function as a controller, driver, sensor, gearbox and actuator. In the picture above, you can see several parts of servo motor components. The motor in a servo motor is a DC motor controlled by the controller, then the component that functions as a sensor is a potentiometer that is connected to the gearbox system on the servo motor

Servo motor is a type of electromechanical actuator that does not rotate continuously such as DC / AC Motor or Stepper Motor, servo motor is used to position and hold several objects. They are used where continuous rotation is not needed so they are not used to control the wheel (unless the servo is modified). Servo can be used effectively here because then there is no need to move in full 360 degrees or they do not require continuous rotation like a wheel. Servo can be ordered to rotate at a certain angle (say 30 degrees) then stay there. Servo also uses feedback mechanisms, so they can sense errors in their position and correct them. This is called servomechanism. So, if the air flow exerts pressure on the steering wheel and deflection or deviation occurs, the servo applies force in the opposite direction and tries to correct the error(Akbar, 2014).

Servo hobby has a motor and control mechanism built in one unit. They have 3 wire connectors. One is for positive supply, and the other is for ground and the last is for control signals.

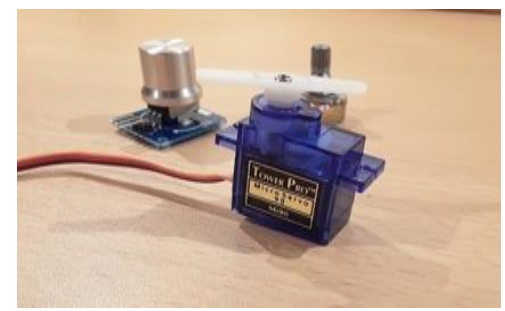

Fig. 8. Servo Motor

\section{Research Methods}

Flowchart is a graphic development of the steps and sequence of procedures of a program. Flowcharts help programmers to solve problems in smaller segments and help in analyzing other alternatives in operation. 


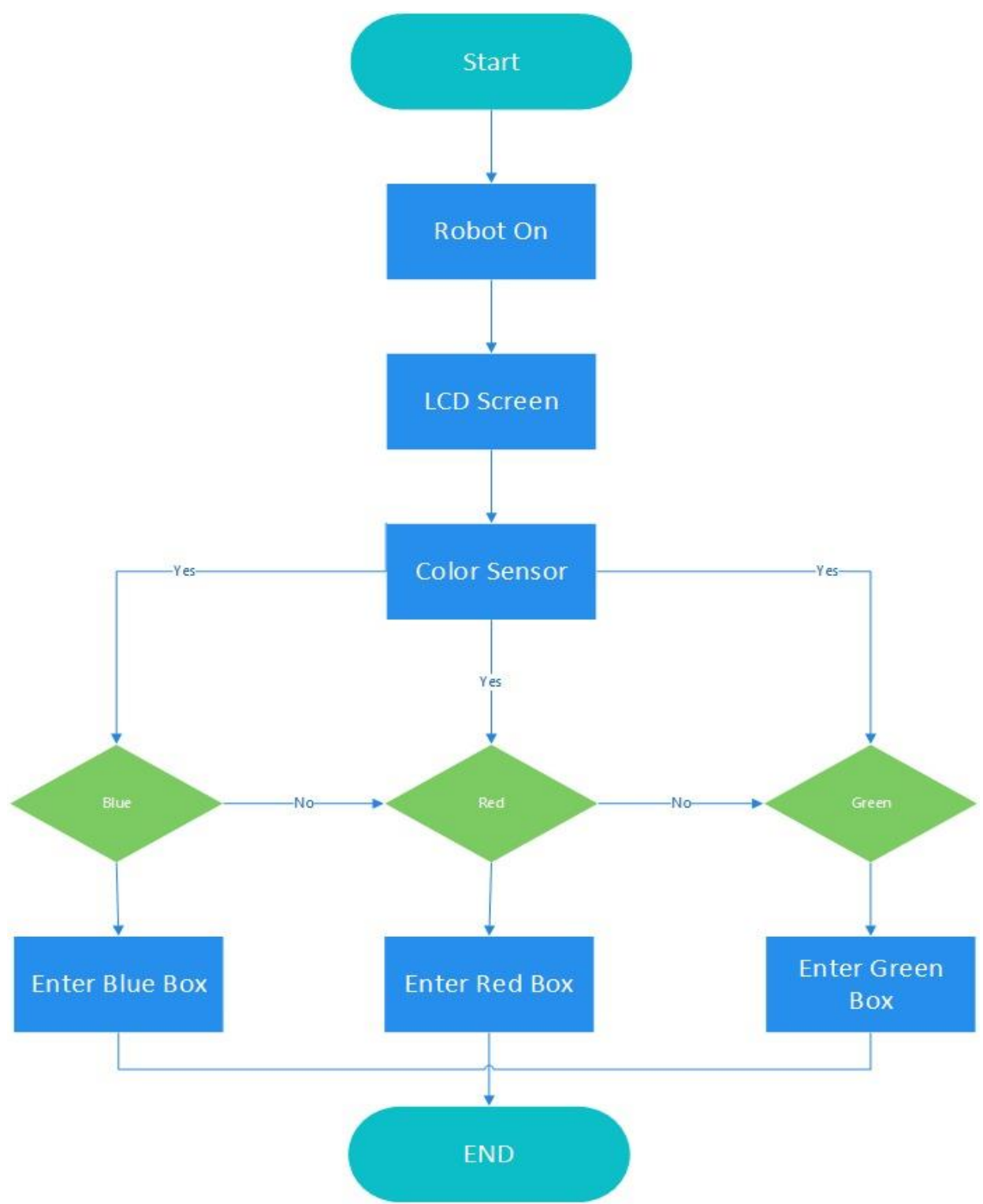

Fig. 9. Research frameworks

\section{Results and Discussions}

Design of Schematic Circuits Interface

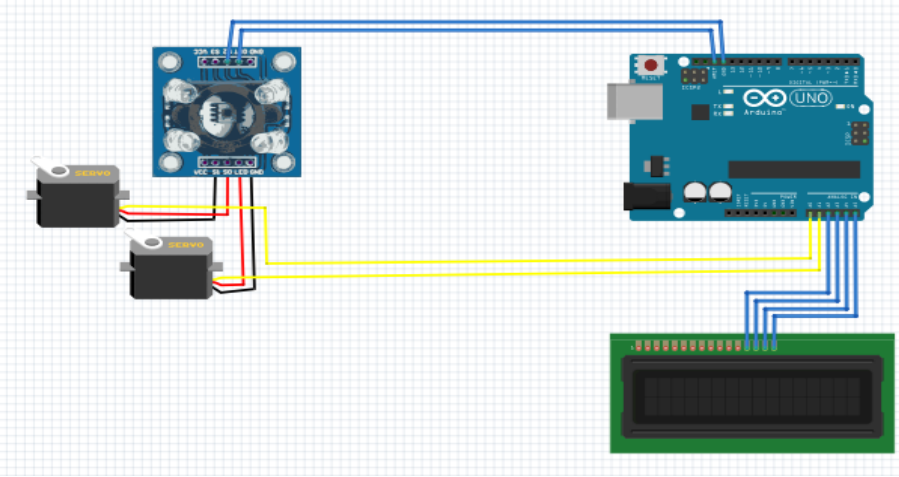

Fig. 10. Color-based Robot Design Scheme 
The circuit schematic includes the processing steps which are a core part of the tool. In this design that needs to be considered is the selection of the components used. The selection of components must be adjusted to the needs in accordance with the design of the tool to be made.

After that, the experiment and testing are carried out to determine the components that will be used. In this design there are several parts, namely Color Sensor, Arduino UNO, Servo Motor and DC Motor.

\section{Making a Circuit}

The manufacture of robots moving goods based on this color through several stages of manufacture. Starting with preparing the materials and tools used. Like setting up the box and arranging the Arduino mainboard, LCD, color sensor. The purpose of making a box is to place the input and output components or as a container of this tool system in order to facilitate and adjust the system in its use. The next process is the electronic schematic assembling process of color-shifting robot goods.

\section{Tools}

At the stage of making this circuit, what is done is to prepare the components that will be used such as color sensors, LCD, Arduino Uno, Arduino supply cable and jumper cable. At Arduino Uno, there is a micromeal controller atmega 328, which has 14 digital input / output pins ( 6 outputs for PWM), and 6 analog input pins. Arduino electronic circuits have several other components such as IC regulators that function as the power supply circuit needs. For color sensor circuits, get an electrical input of $5 \mathrm{~V}$ and use a $5 \mathrm{~V}$ pin to provide input to microcontroller/arduino, on the LCD using A4 A5 pin to provide output.

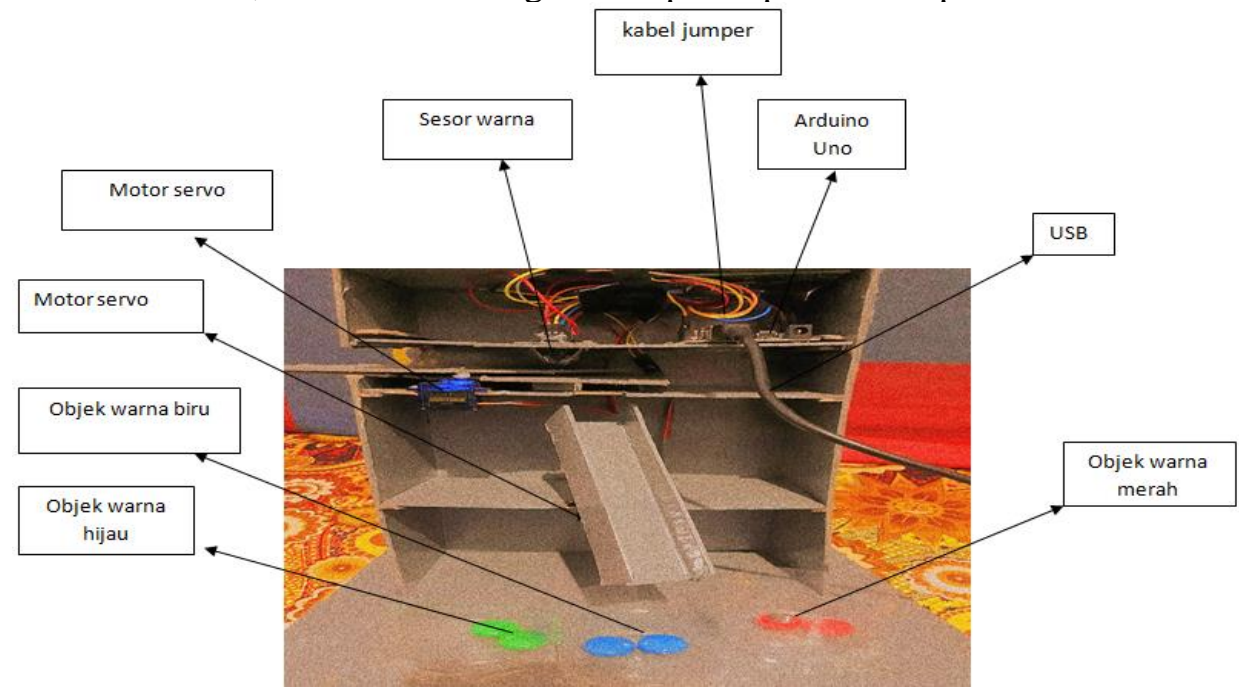

\section{Program Design}

Fig. 11. Series of Robot Moving Goods by Color

The design of the robot program for moving goods based on color consists of several stages. The first process is the creation of flowcharts from color-moving robots, then the program is created using Arduino IDE using $\mathrm{C}$ language and this program will execute commands on the system and tools. Then the program has been uploaded to the microcontroller using Arduino IDE. Furthermore, the microcontroller will read the condition from the color sensor. 


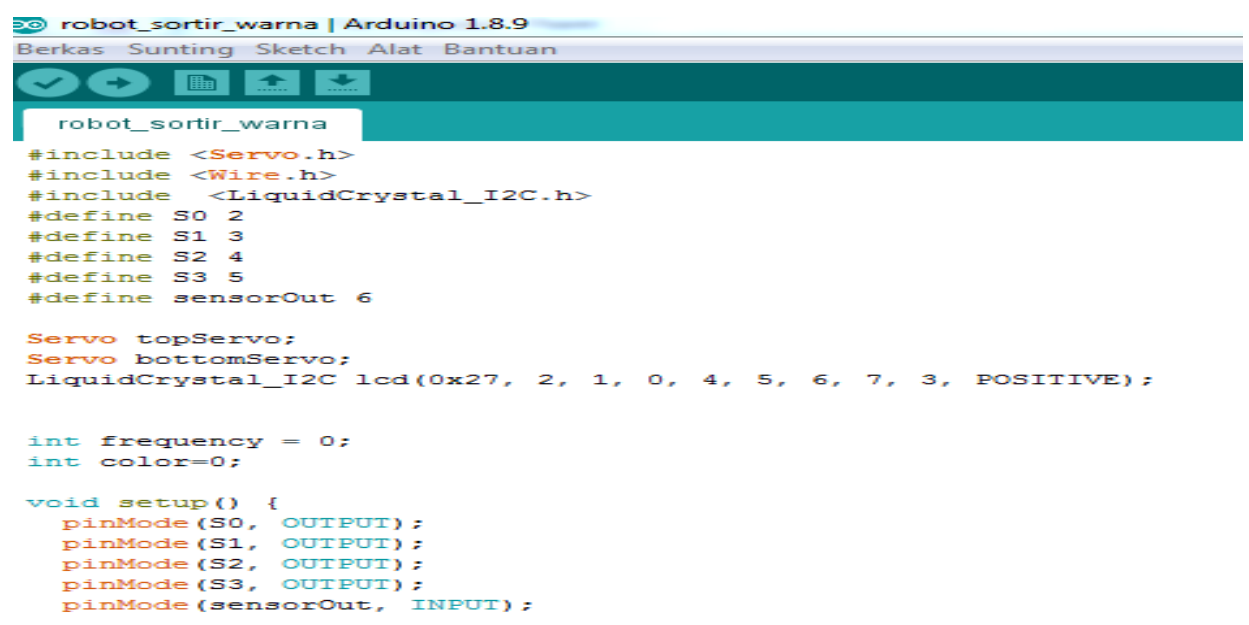

Fig. 12. Program Design

\section{Implementation}

After the system is built based on the designs that have been made, the next step is to upload the program. Connect the USB cable with the Arduino Uno board and on the other side is connected to the computer. Open the Arduino IDE program, then open the sketch of the robot transfer program based on the color that has been made, then press the upload button on the Arduino IDE so that the sketch is transferred from the computer to the Arduino board. After completing the upload, the USB cable can be removed and the robot based on the color transfer tool works by using a 12 volt power supply.

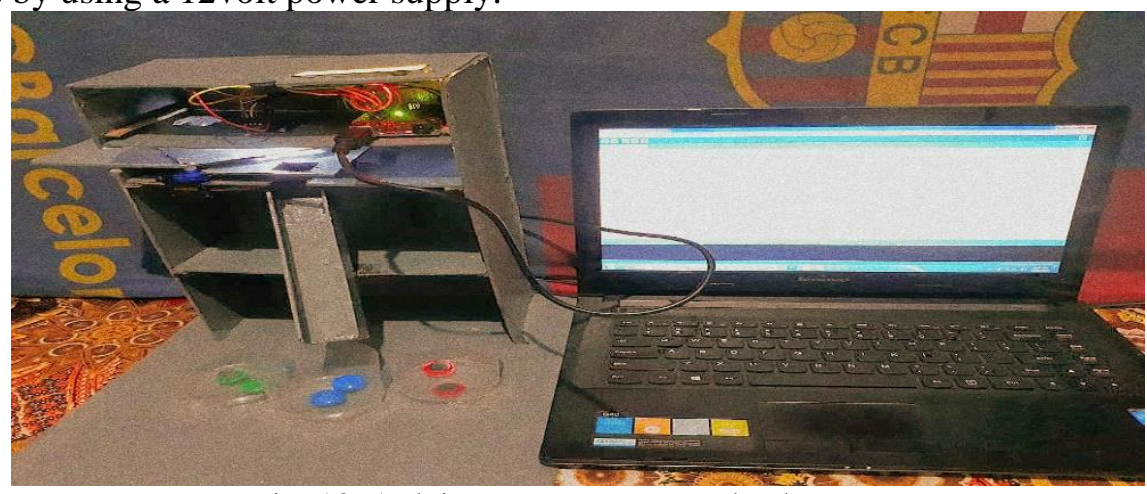

Fig. 13. Arduino IDE Program Upload Process

\section{System Testing}

This test is done using a simulation display by using a color object to detect color. The way this device works is by connecting the Arduino supplay cable. On this device marked with the LCD on. If the initial steps for testing the system have been carried out, then the operation can be done as a product transfer based on color. As the main component of the microcontroller works by running the commands that have been input in the form of coding, where the coding represents the command to run the color sensor. Color sensor as input color object while LCD as output. This device testing simulation aims to see whether the sensor, microcontroller and the program are running well. 


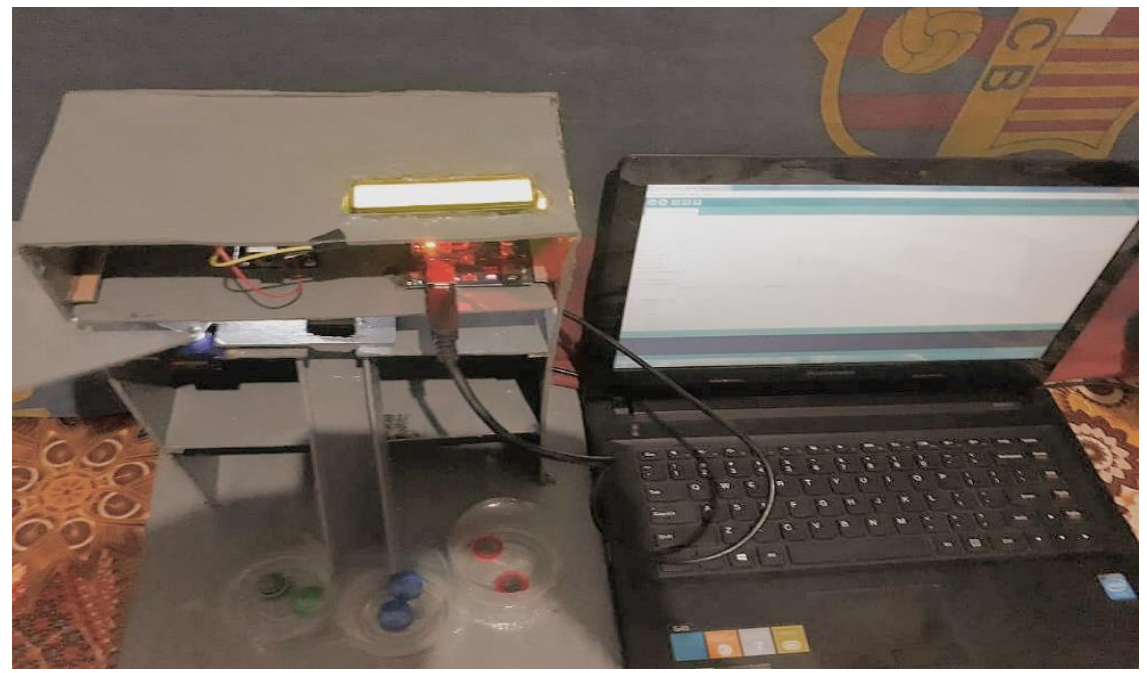

Fig. 14. System Testing

In Figure 14. you can see the main parts installed on this device, namely:

1. Color sensor

2. LCD

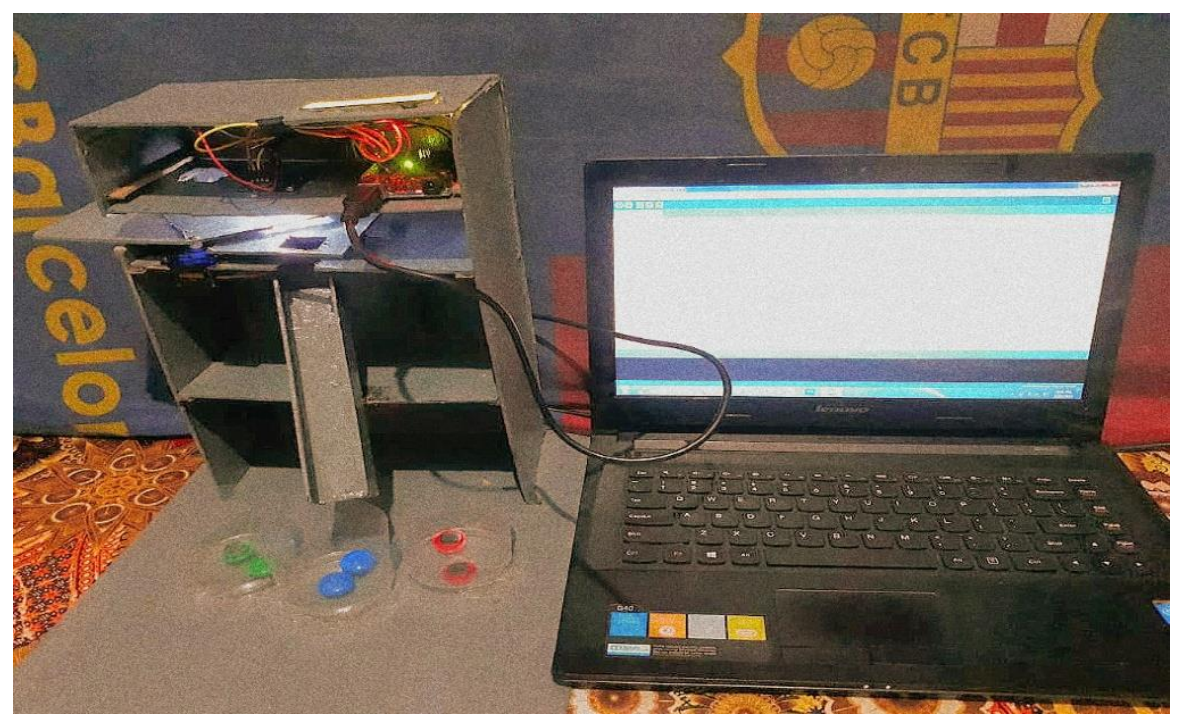

Fig. 15. Series of Tools - Installed Tools

When the microcontroller is working and the sensor is active, the LCD will display a color monitor serial sensor to move things. if the color is detected then the goods will be moved 
according to the command we want. The color-based robot system for moving goods involves Arduino Uno, LCD displays, servo motors and arduino supply cables.

Color Sensor

What is done in this research is to test the removal of color objects according to a predetermined place.

\section{Testing color sensor}

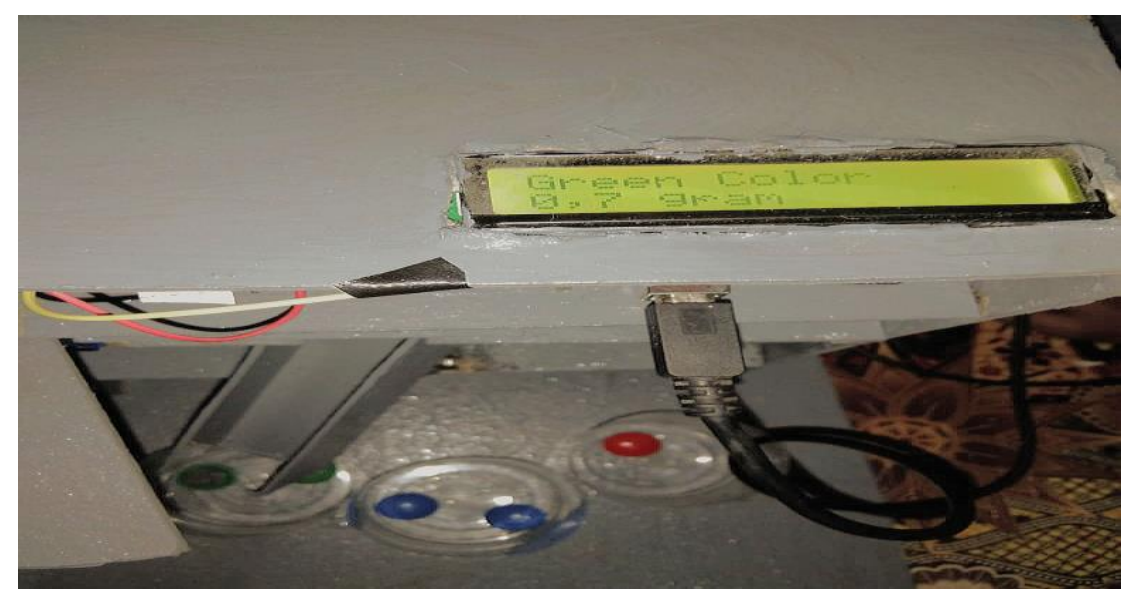

Fig. 16. Testing Sensor green (green)

Figure 16 shows when the color sensor detects green items. If detected or read by a color sensor, the item can be programmed. The following picture

\section{Testing the red that has been programmed}

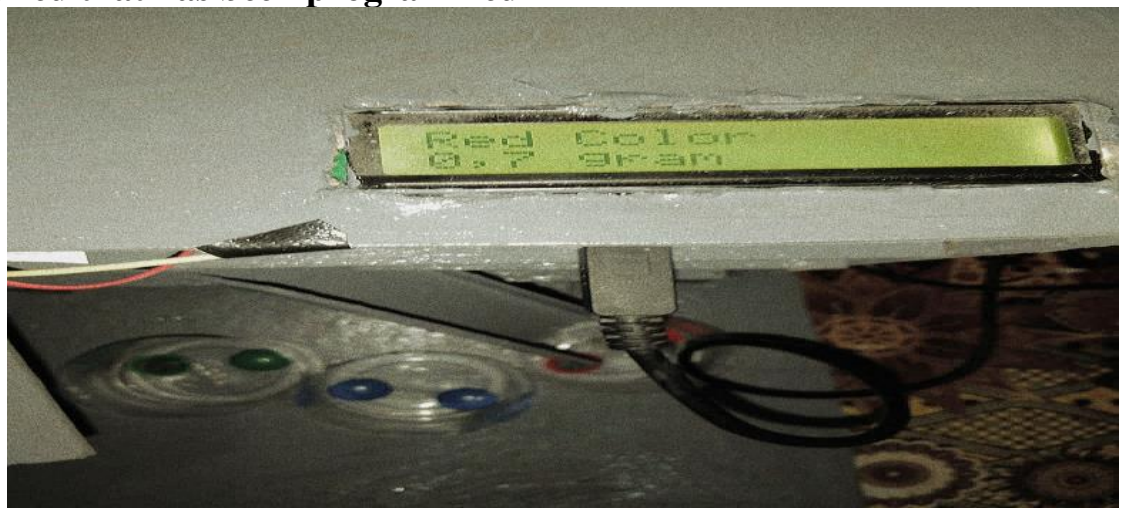

Fig. 17. Red Sensor Testing (red)

Figure 17 shows when the color sensor detects red items. If detected or read by a color sensor, the item can be programmed. The following picture 4.8 testing the blue that has been programmed.

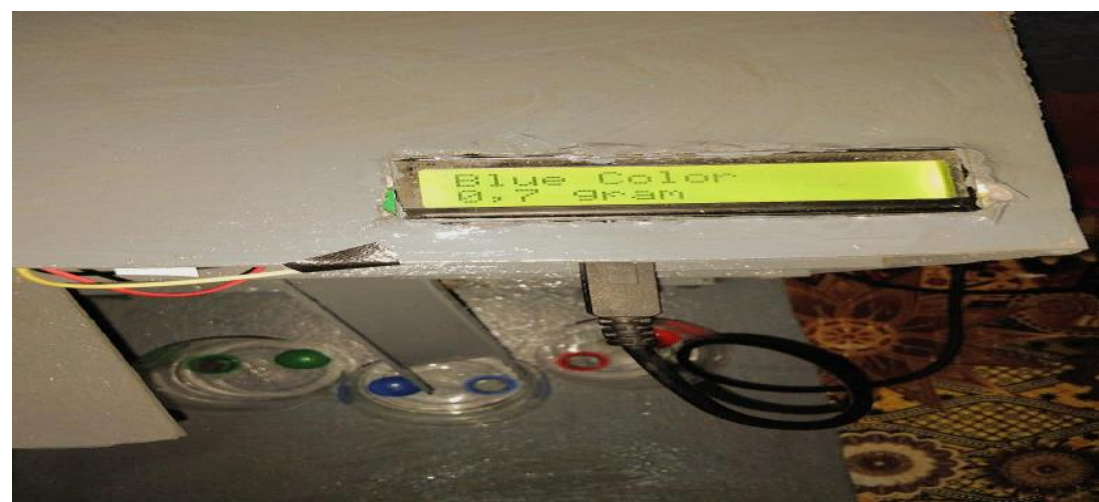

Fig. 18. Testing of blue color sensors 
Figure 18 shows when the color sensor detects blue items. If detected or read by a color sensor, the item can be programmed.

Table 1 - Color Sensor Test Results

\begin{tabular}{cllll}
\hline No & Sensor Color & Weight & LCD Screen & Result \\
\hline 1 & Red & $0,7 \mathrm{~g}$ & Red color & Success \\
\hline 2 & Gren & $0,7 \mathrm{~g}$ & Green color & Success \\
\hline 3 & Blue & $0,7 \mathrm{~g}$ & Blue color & Success \\
\hline
\end{tabular}

\section{LCD testing}

Testing on the LCD as the main display media that functions to display numbers or letters in accordance with the wishes based on the program that we use.

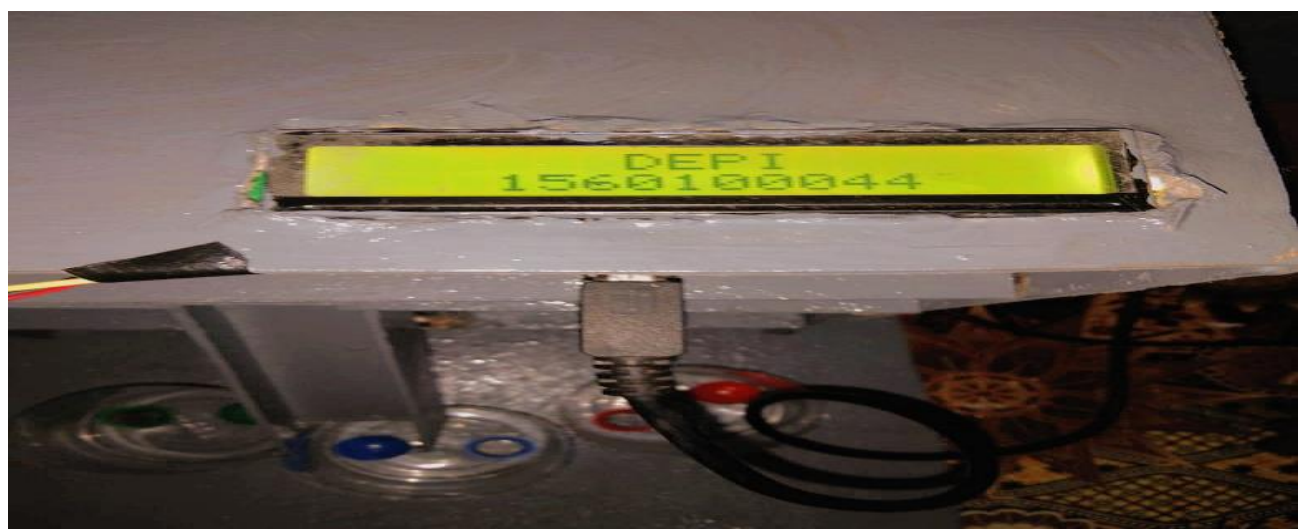

Fig. 19. LCD testing

\section{Conclusion}

Based on the whole system starting from the design and manufacture of tools that have been done, the author has several conclusions ranging from color sensors that function to detect the color that we want and make it easier for us to determine colors that are more practical.

The suggestions for future researchers are:

1. For system development it can be added using information via GSM.

2. Further development can be done by adding a size sensor and load sensor to add functionality and a wider implementation of the robot that has been made.

\section{References}

Akbar, M. A. (2014, August). Simulation of fuzzy logic control for DC servo motor using Arduino based on MATLAB/Simulink. In 2014 International Conference on Intelligent Autonomous Agents, Networks and Systems (pp. 42-46). IEEE.

Boyd, R., \& Holton, R. J. (2018). Technology, innovation, employment and power: Does robotics and artificial intelligence really mean social transformation?. Journal of Sociology, 54(3), 331-345.

Choudhary, M., Narang, R., \& Khanna, P. (2018). Design and Fabrication of a Programmable Selective Sorting System. In Proceedings of the World Congress on Engineering and Computer Science (Vol. 2).

Duan, Y., Edwards, J. S., \& Dwivedi, Y. K. (2019). Artificial intelligence for decision making in the era of Big Data-evolution, challenges and research agenda. International Journal of Information Management, 48, 63-71.

Keisner, A., Raffo, J., \& Wunsch-Vincent, S. (2016). Robotics: Breakthrough technologies, 
innovation, intellectual property. Форсайm, 10 (2 (eng)).

Latha, N. A., Murthy, B. R., \& Kumar, K. B. (2016). Distance sensing with ultrasonic sensor and Arduino. International Journal of Advance Research, Ideas and Innovations in Technology, 2(5), 1-5.

Meijer, G. C. (Ed.). (2008). Smart sensor systems (Vol. 7). Delft, The Netherlands: Wiley.

Petru, L., \& Mazen, G. (2015). PWM control of a DC motor used to drive a conveyor belt. Procedia Engineering, 100, 299-304.

Rahman, M. M., Islam, M. O., \& Salakin, M. S. (2015, May). Arduino and GSM based smart energy meter for advanced metering and billing system. In 2015 International Conference on Electrical Engineering and Information Communication Technology (ICEEICT) (pp. 16). IEEE.

Rajan, C., Megala, B., Nandhini, A., \& Priya, C. R. (2015). A Review: Comparative Analysis of Arduino Micro Controllers in Robotic Car. vol, 9, 371-380.

Sanchez, J., \& Canton, M. P. (2018). Microcontroller programming: the microchip PIC. CRC press.

Sihombing, P., Tommy, F., Sembiring, S., \& Silitonga, N. (2019, June). The citrus fruit sorting device automatically based on color method by using tcs320 color sensor and arduino uno microcontroller. In Journal of Physics: Conference Series (Vol. 1235, No. 1, p. 012064). IOP Publishing. 